\title{
¿QUÉ HISTORIA ENSEÑAR?
}

\section{Julio Valdeón Baruque*}

El título de la charla que me corresponde impartir en estas Jornadas, tal y como figura en los programas, es "Enseñar la historia". No obstante yo voy a efectuar una leve corrección, cambiando ese título por el de " $i Q u e ́$ historia enseñar?", que es, al fin y al cabo, el que inicialmente había propuesto a los organizadores de las Jornadas. De todas formas no deseo, ni mucho menos, plantear un debate a propósito del título, pues lo importante es el contenido de la charla.

De entrada quiero hacer un par de observaciones. Por de pronto me siento abrumado ante el hecho de ocupar el lugar en donde estuvo la víspera nada más y nada menos que el profesor Josep Fontana, una de las personalidades más relevantes de la historiografía española de nuestro tiempo a la par que un auténtico maestro. Asimismo quiero señalar que mi intervención, aunque se sitúe en el marco de unas Jornadas que tratan de "La historia hacia el tercer milenio", no tendrá nada que ver con los problemas de la construcción de la disciplina, sino que se limitará a hacer una serie de reflexiones sobre la historia que se enseña en los niveles educativos secundarios, en la actualidad la ESO y el Bachillerato.

Partiendo de la base de la presencia de la historia en el curriculum de los planes educativos, un hecho incuestionable en la docencia española de nivel secundario de todo el siglo XX, la pregunta que formulo es la siguiente: ¿Qué tipo de historia debe y puede enseñarse al conjunto de los ciudadanos, habida cuenta de que la enseñanza obligatoria llega hoy hasta los dieciséis años?

La historia que se cursa en los niveles secundarios corre a cargo, hablando en términos generales, de licenciados en la disciplina. Ahora bien, el panorama existente desde hace varios años, con los cuerpos docentes prácticamente cerrados, dificulta extraordinariamente la colocación de la mayoría de los uni-

\footnotetext{
* Universidad de Vallalodid
} 
versitarios que cursan la carrera de Historia, tradicionalmente orientados hacia la docencia. Ya sé que, a comienzos de esta década, la Universidad de Deusto publicó un folleto, titulado "La historia subversiva", debido ante todo a la briIlante pluma del profesor Fernando García de Cortázar, en el que se manifestaba que los licenciados en historia, expertos en relaciones humanas complejas, aunque fuera de tiempos pasados, podían prestar excelentes servicios a la sociedad contemporánea, particularmente en el terreno de la política (entendida como todo aquello que tiene que ver con la "polis", no en el sentido partidista). Hace unos años el magnate de la industria italiana Agnelli afirmaba que los licendiados en humanidades le daban un excelente juego al frente de sus empresas. Pero hoy por hoy, al menos en España, los licenciados en humanidades, y en concreto en historia, no encuentran precisamente muchas ofertas de ese tipo.

Pero dejemos la problemática de los licenciados en historia para ocuparnos, tal y como acabo de proponer, de la enseñanza de la disciplina en los niveles educativos de nivel medio. No creo descubrir nada nuevo si digo que la asi gnatura de historia no goza, de partida, de una buena imagen. Frente a asign aturas como las matemáticas, o la lengua española, la historia parece tener $\mathrm{m}$ ás bien un carácter puramente ornamental, como si fuera una disciplina de segunda división. Es más, muchos piensan que el estudio de la historia no requiere la aplicación del raciocinio, sino pura y simplemente de la memorización de lo que se dice en el libro de texto en cuestión, o en su caso de los apuntes tomados al profesor de turno.

Sin embargo, en los últimos meses del año 1997, tras el intento fallido, por parte del Ministerio de Educación y Cultura, de modificar el decreto de mínimos del área de "ciencias sociales, geografía e historia" de la ESO, vigente desde junio de 1991, se produjo en el seno de la sociedad española un debate a todas luces espectacular. Entre finales de octubre y finales de diciembre del mencionado año 1997, aparecieron en la prensa española alrededor de setecientos artículos a propósito de la enseñanza de la historia. De pronto daba la impresión de que aquel era uno de los asuntos cruciales de la vida española. No sólo parecía haber dejado de ser la historia una asignatura decorativa, sino que, a juzgar por la polémica desatada, el qué y el cómo de la enseñanza de esa disciplina en la ESO resultaba ser poco menos que una cuestión de vida o muerte para el futuro de la sociedad española. Ni que decir tiene que en buena medida ese debate obedecía a razones de índole política, más que propiamente académicas o pedagógicas.

Mi punto de partida es claro. La historia no puede faltar, en modo alguno, en los estudios dirigidos al conjunto de los ciudadanos. Ello es así porque la historia es la disciplina que atañe a la propia vida de los seres humanos, considerados como sociedad y contemplados en su desarrollo temporal. Somos parte de la naturaleza, al igual que los otros seres vivos, pero además tenemos histo- 
ria. La historia es, en definitiva, el territorio peculiar del ser humano. Por lo demás, Emilio Lledó dixit, "Ser es, esencialmente, ser memoria". De ahí que resulte imposible entender nada de los que nos rodea si no tenemos en cue nta su trayectoria histórica.

Ahora bien, lo que se transmite en los centros educativos a propósito de la historia de la humanidad ha de ser, necesariamente, una brevísima síntesis de algunos de los elementos más significativos de esa trayectoria, que es, por supuesto, de todo punto inabarcable. ¿Qué aspectos concretos de la historia debemos enseñar? ¿Una lista de monarcas de un determinado país, por ejemplo los famosos "reyes godos", de acuerdo con el tradicional tópico? ¿Una historia reducida a los grandes personajes y a los acontecimientos políticos y militares de alto rango? ¿Una historia de cuestiones parciales o que tienda a la totalidad? ¿Una historia ceñida a las modas del momento, ya sean éstas, en una época, la sociedad y la economía y en otra las mentalidades y la vida cotidiana? ¿Una historia universal, de Europa, de España, de la región específica o de la localidad en que se sitúa cada centro docente? ¿No será necesario tratar de buscar un equilibrio entre todas esas posibles perspectivas? Y, por otra parte, ¿de qué manera hay que llevar a cabo esa enseñanza? ¿De qué procedimientos hay que valerse? ¿Con qué recursos didácticos tiene que contar el profesor para desarrollar eficientemente su labor? ¿Qué actividades hay que poner en marcha? En definitiva, ¿qué hay que enseñar de la historia y cómo hay que enseñarla?

Raimundo Cuesta, un profesor de historia de secundaria que ha demostrado una gran preocupación por la enseñanza de la disciplina, ha señalado en una obra reciente, sin duda de gran interés, que en los institutos de bachillerato de la primera mitad de este siglo, tomados como modelo de centros de educación secundaria, se impartía una "historia sin pedagogía", en tanto que en las escuelas de educación primaria de esa misma época lo que se enseñaba era una "pedagogía sin historia". Lo que quiere decir dicho autor es que los catedráticos de instituto de la asignatura que nos ocupa intentaban reproducir en las aulas de secundaria el modelo universitario, lo que se traducía en la orientación de sus clases como si fueran exposiciones magistrales y en la despreocupación más absoluta por el aprendizaje de sus alumnos.

Esta situación perduraba, más o menos, en la década de los sesenta. En verdad la enseñanza secundaria, hasta esas fechas, la había cursado una pequeñísima fracción de la población española. Pero los cambios producidos en la sociedad, la marcha hacia lo que Cuesta Ilama la "sociedad tecnocrática de masas", exigieron modificaciones educativas. Su plasmación fue la Ley General de Educación del ministro Villar Palasí. Quizá la principal novedad de esa ley era que la enseñanza obligatoria se prolongaba hasta los catorce años.

En la década de los setenta y de los ochenta una serie de fenómenos de muy diversa naturaleza, política, social o meramente intelectual, derivaron en la 
modificación de los sistemas educativos de buena parte del continente europeo, pero a la vez influyeron, en distinta medida, en la manera concreta de enfocar la enseñanza de la historia. Recordemos, por ejemplo, el importantísimo debate que, a propósito de la enseñanza de la disciplina que nos ocupa, tuvo lugar, entre otros países, en los años setenta, en Francia, Inglaterra, o Alemania. Se criticaba, en particular por los sectores más progresistas de la sociedad, la forma tradicional de enseñar historia, no sólo por su carácter memorístico y por su insistencia en los llamados grandes personajes del pasado sino, ante todo, por su estrecha vinculación con los estados-nación, por su condición de sierva del nacionalismo en suma. Seguía enseñándose una historia vieja y apergaminada, lo que dejaba indiferente, sobre todo en lo que a su concienciación social e ideológica se refiere, a la juventud, deseosa de participar en la propuesta de renovación del mundo. En ese contexto se entiende que la enseñanza tradicional de la historia se viera con ojos sumamente críticos. Por supuesto, también desempeñó su papel el estallido que se vivió en París y otras ciudades francesas en mayo del 68 y del que los estudiantes fueron los protagonistas por excelencia.

La historia, se decía por los sectores más críticos, hay que entenderla no como un relato de hechos pretéritos, sino como una ciencia social, conectada, por lo tanto, con las otras ciencias sociales. Ciertamente se admitía que a los jóvenes les interesaba tener determinados conocimientos del pasado del mundo. Pero lo esencial no era saber el nombre de algún emperador romano, $o$ quien fue Carlomagno o Napoleón, sino conocer el funcionamiento del mundo en el que uno vive, la implicación entre la vida económica, la política, la cultura, las mentalidades, etc. Así las cosas, la concepción de la historia enseñada como un relato de hechos del pasado, protagonizados por destacados personajes, iba desapareciendo, para convertirse en una disciplina que reflexionaba sobre problemas concretos de naturaleza social, política, antropológica, etc. de la sociedad humana. Eso explica, por ejemplo, que el propio nombre de historia, de siempre ligado en el ámbito docente a la geografía, fuera sustituido por el más amplio de "ciencias sociales". Francia fue, en esa orientación, un país pionero.

España, no lo olvidemos, vivió hasta 1975 bajo la dictadura de Franco. Pero antes de esa fecha comenzaron su despliegue diversos grupos de renovación pedagógica, integrados, en buena medida, por jóvenes profesores de bachillerato. A título de ejemplo mencionaremos uno de ellos, el denominado Germanías, que efectuó propuestas muy sugestivas. La pretensión de esos grupos era poner fin a la "historia sin pedagogía", de que antes hemos hablado. La historia que ellos querían enseñar no sólo tenía que ser más viva y más participativa, sino que debía afectar a problemas concretos del ser humano. Es evidente que, en el caso español, esos movimientos solían tener una clara connotación democrática, lo que suponía una inequívoca oposición al régimen franquista. Ahora bien, en España se añadía un elemento singular, ausente en otros países 


\section{¿QUÉ HISTORIA ENSEÑAR?}

de Europa. Nos referimos a la reivindicación autonomista de determinados territorios, sobre todo aquellos que, además de poseer un idioma propio, habían contado con un Estatuto durante la Segunda República. Ese asunto, originariamente de naturaleza política, repercutía directamente en el terreno educativo, y en particular en la enseñanza de la historia, que variaba en función de la perspectiva específica de cada uno de esos territorios.

A todo lo señalado es preciso añadir, asimismo, la incidencia creciente de otro factor. Me refiero al papel de los pedagogos y de los psicólogos del aprendizaje, deseosos de aportar sus conocimientos para mejorar la actividad docente. En principio este factor resultaba positivo. No obstante, lo preocupante fue, tal es al menos mi punto de vista, la obsesión de algunos sectores del profesorado por el "formalismo pedagógico", que no hay que confundir en ningún caso con el interés pedagógico, de todo punto legítimo. Actuando a modo de fanáticos conversos, algunos docentes se enfrascaron en la nueva terminología. Todo consistía en elaborar diseños curriculares, señalar objetivos, fijar los contenidos conceptuales, procedimentales y actitudinales, especificar los criterios de evaluación, etc. El dominio de esta especie de escolástica parecía garantizar el éxito docente, aunque luego sólo se enseñaran cosas vacías. El "cómo" enseñar, según apuntó certeramente en un artículo aparecido en "El País" (10 de marzo de 1987) Fernando Arroyo, director del Instituto de Ciencias de la Educación de la Universidad Autónoma de Madrid, había anulado al "qué" enseñar.

La conjunción de los elementos señalados motivó que se viviera una etapa, en el caso español retrasada, por razones obvias, hasta la década de los ochenta, caracterizada por la puesta en marcha de nuevas experiencias educativas. Fueron los años en que se ensayó la "reforma", con frecuencia dando palos de ciego, pues lo que un día parecía la gran revelación al siguiente se abandonaba por utópico o por disparatado. Recordemos, a título de ejemplo, la adoración inicial por las doctrinas psicológicas de Piaget. Basándose en su afirmación de que sólo es posible un pensamiento lógico-formal hacia los dieciséis años se llegaba a la conclusión de que enseñar historia antes de esa edad no tenía el menor sentido, pues lo único que harían los escolares es memorizar cosas incomprensibles. Los ensayos desembocaron, finalmente, en la LOGSE, la ley actualmente en vigor.

Sería muy prolijo detenerse en la forma en que esas modificaciones en curso afectaron a la enseñanza de la historia. Pero veamos algunos aspectos. Se ponía de tal manera el acento en "cómo" enseñar, que prácticamente se prescindía de "qué" enseñar. En el caso de la historia los contenidos eran prácticamente indiferentes. Lo importante era que los escolares sacaran consecuencias útiles del estudio de casos del pasado, pero esos casos lo mismo daba que fueran sucesos considerados tradicionalmente de gran trascendencia, como por ejemplo la revolución francesa, o una curiosa historieta local. Incluso se ofrecían ejemplos sobre países inventados, con cifras imaginadas de población o 
de producción, pues lo que interesaba, se decía por los defensores de esas propuestas, era que los alumnos se acostumbraran a manejar las relaciones entre variables demográficas, económicas, sociales, etc. La idea de la interdisciplinariedad contribuía, en no pequeña medida, a potenciar el área de "ciencias sociales". Claro que, en flagrante contradicción con esta orientación, se potenciaban simultáneamente asignaturas como "música", al fin y al cabo una parte del arte.

Item más. La crítica a la historia estaba presente en los propios altos cargos del ministerio, léase el Ministro de Educación del primer gobierno socialista, José María Maravall, o el Director General de Enseñanzas Medias, José Segovia. Este último afirmaba que ya estaba bien de aprender listas de reyes y de batallas, si luego se ignoraba cómo había que votar, qué era una letra de cambio o en qué consistían las normas de tráfico. Esas cuestiones parecían vitales, pero al no estudiarse en ningún área concreta se pensó que lo idóneo era que la tradicional de geografía e historia, ahora convertida en "ciencias sociales", es decir algo progre y moderno, orientara sus objetivos en esa dirección, la de formar ciudadanos, los cuales debían de conocer aquellas cuestiones que se supone son imprescindibles para la vida contemporánea. Así las cosas, al profesor de geografía e historia de tiempos pasados, transformado en un docente de "ciencias sociales", se le endosaba la tarea de formar poco menos que la conciencia cívica de sus alumnos. ¿No son también los profesores de dicho área los que preferentemente imparten una asignatura optativa de la enseñanza secundaria, que se denomina "relaciones entre la mujer y el hombre", y en la que figuran temas como "el ligue"?

En ese contexto se explica que surgieran proyectos, al calor de la reforma educativa, de los más variopinto. Uno de ellos, por ejemplo, es aquel que propone el estudio de la historia al margen de la cronología. ¿Cómo es esto posible? Los defensores de este proyecto parten de un burdo presentismo, apoyándose en el principio de que el pasado histórico, lo mismo si se remonta a los tiempos paleolíticos que si se refiere a los años ochenta de este siglo, se encuentra todo él en un mismo plano. Al mismo tiempo se insiste en que lo importante del estudio de la historia es obtener experiencias provechosas acerca de los distintos planos en los que se desenvuelve la vida de los seres humanos, ya sea el de lo económico, el de lo social, el de lo político o el de lo cultural. Así las cosas, la historia, en la propuesta que comentamos, se estudia dividida en esos cuatro apartados citados, escogiendo de cada uno de ellos algunas muestras significativas.

Una posible secuenciación en el estudio de la disciplina sería, por ejemplo, la siguiente: para comenzar estudio de la revolución industrial, como muestra de la proyección económica de los seres humanos; a continuación análisis de un tipo de sociedad histórica, "verbi gratia" la feudal; luego se pasaría al terreno político, que podría estar representado, escojamos un modelo cualquiera, 
por la Atenas de Pericles; finalmente, el Renacimiento podría constituir, i por qué no?, un ejemplo altamente significativo de la actividad cultural que son capaces de desarrollar los seres humanos.

Lo señalado hasta aquí, simple botón de muestra de lo que la reforma educativa ensayada en España en los años ochenta supuso para la enseñanza de la historia en los niveles secundarios, ofrece suficientes elementos para enten der por qué, en diversos sectores de profesionales de la disciplina, se gestó una seria preocupación acerca del futuro que le aguardaba a Clio, si las cosas seguían discurriendo por esos caminos.

Por de pronto, la disputa surgida en Francia, Alemania o Inglaterra a pro pósito de la enseñanza de la historia en los niveles educatuivos medios, había evolucionado claramente en el sentido de defensa firme de la disciplina. En el coloquio de Pau del año 1979, dirigido por el inolvidable Manuel Tuñón de Lara, Pierre Vilar manifestó, en referencia a los ensayos puestos en marcha en Francia en la década de los setenta, que se corría el peligro de sustituir la enseñanza de la historia "por una mezcla de vulgaridades económicas, sociológicas, psicológicas" (Historiografía española contemporánea, Siglo XXI, Madrid 1980, pág. 139). Sumamente expresivo fue, por su parte, el historiador alemán Jürgen Kocka, el cual, al aludir a lo sucedido en su país en los años setenta, afirmaba: "No sin razón se temió que los funcionarios de la cultura y la enseñ anza -que se creían progresistas- redujeran la historia a la historia reciente y la degradasen en cierta forma a la condición de sierva de las ciencias sociales sistemáticas" (Historia Social. Concepto. Desarrollo. Problemas. trad. española, Alfa, Barcelona 1989, pág. 163).

En la década de los ochenta hubo en España quienes propusieron organizar el área a partir de lo que denominaban "los núcleos conceptuales básicos de las ciencias sociales". Podría comenzar el estudio por temas como la familia, el barrio, el pueblo, la ciudad, la región, la nación, etc. y continuar por la producción, el consumo, las relaciones sociales, las diversiones, etc. En cada uno de esos temas habría, a modo de introducción, una breve referencia histórica. Mas la historia, entendida como el proceso seguido por la humanidad desde sus orígenes hasta la actualidad, habría desaparecido por completo, quedando reducida simplemente a pequeñas anécdotas aisladas, relativas a ese abanico de temas de estudio.

De todas formas es cierto que al final, es decir en la LOGSE, la historia no quedó tan desdibujada como pudo temerse en algunos momentos. Lo esencial del área de "ciencias sociales, geografía e historia" son estas dos últimas disciplinas, porque, al menos así se dice en la literatura que acompaña al diseño curricular básico del Ministerio de Educación, son las únicas ciencias sociales que tienden a la universalidad y son, por otra parte, las que poseen una mayor tradición pedagógica. Es más, lo que figura de historia en el mencionado curriculum, independientemente de su posible o real vaguedad e inconcreción, apa- 
rece ordenado en un orden cronológico riguroso, pues arranca de los tiempos prehistóricos y concluye en el mundo en que vivimos.

Ello no obsta, sin embargo, para intentar señalar las deficiencias observadas en el curriculum del área, en general, y en lo que respecta a la historia, en particular. Existe, como es sabido, un decreto de mínimos, en el que se incluye aquellos aspectos que se estudiarán en cualquier parte del territorio español. Ese decreto afecta a un $55 \%$ o a un $65 \%$ del total del curriculum, según se trate de una comunidad autónoma con lengua propia o no. El resto del curriculum es fijado por la respectiva comunidad autónoma, allí donde tiene competencias. Aquí se encuentra, sin la menor duda, uno de los principales caballos de batalla de la reciente discusión a propósito de la enseñanza de la historia. El decreto de mínimos es sumamente vago, reduciéndose en ocasiones a títulos tan etéreos como el siguiente "transformaciones de la España contemporánea". Eso explica que haya libros de textos de determinadas comunidades que "de facto" sólo hablan de lo sucedido en tal o cual territorio de España. Y no hablemos de las posibilidades que se le ofrecen a un profesor en el aula. Al fin y al cabo ya señalaron en su día los profesores Abilio Barbero y Marcelo Vigil que una cosa era la legitimidad de los pueblos de España a tener autonomía y otra muy diferente que "diversas áreas geográficas de la Península puedan ser consideradas igualmente como unidades de destino en lo universal con constantes históricas milenarias" (La formación del feudalismo en la Península Ibérica, Crítica, Barcelona 1978 pág. 20). Pues bien, para la consecución de esos propósitos la historia es, sin duda alguna, un arma privilegiada, lo que explica, en buena medida, la reacción habida, básicamente en ciertas comunidades autónomas, ante el proyecto de modificación del decreto de mínimos.

Mi posición, a propósito de la enseñanza de la historia en los niveles secundarios, es clara. Defiendo una historia que, por de pronto, se base en la cronología, comenzando por los primeros seres humanos y concluyendo en nuestro tiempo. Es posible que el hilo conductor del proceso deban de ser los grandes hitos de la memoria colectiva, ya se trate, por acudir a algunos ejemplos representativos, del imperio romano, la revolución francesa, la independencia de América, etc.. Pero eso no quiere decir, ni mucho menos, que la historia que ha de enseñarse a los niños de 12 a 18 años tenga que reducirse a nombres $y$ datos. Una cosa es que no exista historia sin acontecimientos, y otra muy distinta que el estudio del pasado se limite a los grandes eventos. El objetivo último de todo profesor de la asignatura que nos ocupa es explicar una historia total, por más que este propósito tenga una notable dosis de utopía.

En la enseñanza primaria se estudia el medio, natural, social y cultural. Pero en la ESO, al menos yo lo pienso así, el camino ha de ser inverso: de lo general a lo particular. Ese horizonte general no es otro sino la historia universal, por más que en el caso español lo europeo tenga un peso determinante. En segundo lugar se situará el horizonte global español y, en última instancia, aparece- 
¿QUÉ HISTORIA ENSEÑAR?

rá el referente de la región, comunidad autónoma, nacionalidad, o como qu iera que se denomine el territorio en el que vive el alumno. Lo local puede servir como elementos de ejemplificación, o para la realización de pequeños trabajos, digamos de investigación. Pero eso sí, lo local ha de estar en todo momento subordinado a los referentes generales, pues de lo contrario se corre el riesgo de terminar descubriendo el Mediterráneo, como sucede tan a menudo.

Llegados a este punto, no puedo por menos de manifestar mi admiración por el modelo educativo francés. A mediados de los años ochenta, siendo Ministro de Educación Chevenement, después de la ofensiva desplegada por los historiadores franceses y de la creación de comisiones que evaluaron los resultados de las reformas emprendidas una década antes, se decidió reforzar la enseñanza de la historia. Lo cierto es que hoy en día desde la escuela primaria los niños franceses ya estudian "geografía e historia", asignatura diferente de otra denominada "educación cívica", en donde tienen cabida aquellas cuestiones que en España se endosaron a los docentes de geografía e historia. Por lo demás la historia que empiezan a estudiar los niños franceses se basa en la cronología. En un primer momento se efectúan rápidos y ligeros recorridos, que comienzan en la prehistoria y llegan hasta la actualidad, fijándose en aspectos de gran sencillez, como los relativos a la vida cotidiana. Luego se Ilevan a cabo nuevos recorridos del proceso histórico, si bien añadiendo aspectos progresivamente más complejos. Así las cosas, al llegar al período escolar equivalente a nuestra ESO los escolares franceses abordan el estudio de la historia más en profundidad, parcelada de acuerdo con la evolución cronológica (Prehistoria y Antigüedad en $6^{\circ}$, Edad Media y comienzos de la Moderna en $5^{\circ}$, etc.). No se rechaza en Francia, ni mucho menos, el acudir a la historia local, pero siempre que se limite a una parte reducida del curso.

Una última cuestión. ¿Enseñanza por descubrimiento o por transmisión? No quiero, ni puedo, por falta de competencia, entrar en un debate pedagógico de tanta complejidad como el que se plantea en esa pregunta. De todas formas pienso que ambos métodos pueden complementarse. Sin duda la experiencia del profesor ha de ser aprovechada, sacando partido de sus explicaciones, de su labor de "transmisión" del conocimiento, en definitiva. Ahora bien, hay que cultivar, al mismo tiempo, la disposición de los estudiantes a buscar las cosas por sí mismos, a "descubrir" nuevas parcelas de la disciplina de que estamos tratando. Pero, por favor, hay que evitar caer en el ridículo. Estoy pensando en la idea expresada hace unos años en una revista de temas educativos en la que se decía que había llegado el momento de que los niños conocieran la historia por sí mismos. Frente a la clase del profesor, dogmática por definición, así se decía en ese artículo, el alumno acudiría a los textos históricos para conocer cómo fue "realmente" el pasado de la humanidad. Sin comentarios. 
